\title{
Designing Educational Research Roadmap
}

\author{
Mochamad Nursalim ${ }^{1, *}$ Wagino $^{2}$ Febrita Ardianingsih \\ Irena Y. Maureen ${ }^{4} \quad$ Supriyanto $^{5}$ \\ ${ }^{1}$ Guidance and Counselling Department, Faculty of Education, Universitas Negeri Surabaya \\ ${ }^{2,3}$ Special Education Department, Faculty of Education, Universitas Negeri Surabaya \\ ${ }^{4}$ Educational Technology Department, Faculty of Education, Universitas Negeri Surabaya \\ ${ }^{5}$ Educational Management Department,Faculty of Education, Universitas Negeri Surabaya \\ *Corresponding author. Email: mochamadnursalim@unesa.ac.id
}

\begin{abstract}
The research aims to roadmap educational science research that meets the criteria of acceptability to guide, direct and enhance research on educational science. This research is development research with procedures referring to the ADDIE approach (Analyze, Design, Develop, Implement, Evaluation). The data obtained will be analyzed both qualitatively and quantitatively. Based on the results and discussion, the following conclusions can be formulated. 1). Based on the above need assessment, it can be concluded that it is necessary to develop an educational science research roadmap to guide, direct and improve research on educational science, which in turn can clarify and improve the existence of educational science, 2) The educational science research roadmap developed applicable, highly feasible and highly appropriate, 3) the educational science research roadmap developed can guide and be a handle for the entire academic community of FIP in particular to meet the standards of eligibility. Based on the above conclusions, the following suggestions are formulated. 1) The prepared roadmap has met the acceptance criteria; therefore, the draft academic roadmap that has been prepared needs to be further processed to obtain approval from the Faculty Senate and Dean of FIP Unesa, 2) There needs to be dissemination to the academic community about the research roadmap that has been prepared so that the prepared roadmap can guide, direct and improve research on educational sciences, which in turn can clarify and improve the existence of educational sciences, 3) To complete the roadmap of educational science research, it is also necessary to compile PKM roadmap conducted by the academic community.
\end{abstract}

Keywords: Roadmap, Research, Education, UNESA.

\section{INTRODUCTION}

Educational science is a process of scientific thinking (critical, methodical, and systematic thinking) about the reality that we call education. Thus, the main problem of science is the dynamic phenomenon of education and all aspects related to education [1]. For this reason, educational science uses an open approach in its development [2].

Education is expected following Indonesian society by Tilaar [3] called "transformative pedagogy." Meanwhile, the author who is similar to Tilaar, calls the new science of education with the term "dialectical education science". Named dialectic because education science needs to constantly dialogue with the philosophy of education, including with the Indonesian national philosophy of education (needs to be compiled and developed) and various streams of educational philosophy from outside to support its substantive and normative concepts, in order to enlighten humanity, which culminates in the attainment of the highest possible security and happiness or to attain perfect happiness in the unity of a dynamic, harmonious organization.

In addition, the science of education needs to be constantly harmonious with the foundations of education (including the various paradigms in it) that are more "practical theories" to strengthen its relevance to face the challenges of the times in reaching the mouth of education.

Hendrowibowo [4] states that Science in Education or Pedagogy is a science that has been developed for a long time-derived from the word pedagogy, which means educating. Education Science meets the requirements as a science-based on epistemology, ontology, and axiology. However, the results of a literature review conducted [4], since the end of the 20th century, the existence of educational science is increasingly unclear, 
this is supported by the non - inclusion of Pedagogy (term Educational Science) in the Encyclopedia of the Scientific Revolution in 2000, this means that Educational Science experienced the evolution of ambiguity, both in Indonesia and internationally. Komar [5] tried to explore the scientific area of Education and found that the development of education is still vulnerable to challenges and opportunities. The development of education needs to relate to other disciplines such as Psychology, Anthropology, Sociology, Economics, and Biology.

To support the development of Education Science, FIP Unesa has developed a Research Master Plan (RMP) for 2016-2020; RMP FIP Unesa is a strategic formulation in determining the direction and policy of research in FIP Unesa to increase the role of research to support the achievement of Unesa's vision. To further improve the RIP that has been prepared, it is necessary to follow up by compiling a roadmap (road map) that includes basic research ( $\mathrm{R} \& \mathrm{D})$, applied research, and development research. Educational science research roadmap is a milestone of research activities conducted by researchers in a mono, multi, or inter-disciplinary period.

Roadmaps were quite popular in the US in the late 1990s and are evolving in Europe [6]. Initially, roadmaps were only applied to the technological field. A roadmap is a strategic approach to planning the future of technology in various sectors, such as learning design [7], research [8], and cloud computing [8]. The main benefits of the technology roadmap are to provide information to make better investment decisions by identifying critical technologies and technology gaps and identifying ways to increase $R \& D$ investment to open new frontiers in the region.

According to some authors, the roadmap is good planning [7], [9]. A roadmap is a far-sighted view of a selected field of research consisting of a highly intelligent collection of knowledge and imagination that drives change in a field [8]. Some examples of roadmaps: research roadmap, industry roadmap, technology roadmap, product roadmap.

A research roadmap is a mind map and existing research results related to research themes, research results that have been done by previous researchers and their position in the mind map, future external development plans, plans, and stages of research to support the external to be achieved [10]. Another definition from Kim et al. [11] Roadmaps are popular metaphors for planning and illustrating the use of scientific and technological resources, elements, and structures of relationships over a while. The roadmap process involves identifying, evaluating, and selecting strategic alternatives that can be used to achieve the desired goals, and the resulting roadmap summarizes and communicates the results of crucial business decisions.

It can be concluded that a research roadmap is a detailed work plan that describes what needs to be done to achieve the objectives of the research. From most definitions, it can be said that a roadmap should reflect the knowledge/vision of a group of visionaries and experts. In other words, the roadmap assessment can only be done by the experts who have a broader view and better understanding of education.

The purpose of the roadmap is to outline a research agenda that will guide the development of specific research programs to be conducted, both within and across disciplines, to provide answers to current scientific questions, reduce scientific uncertainty, and provide a solid scientific foundation for future policy development [12] [13].

According to Camarinha [6], the roadmap consists of three main components: (1) formulating a baseline of current conditions, (2) the desired vision or "future", and (3) a series of structured actions to achieve that vision. The roadmap is divided into three main sections: 1) Review of Current Issues, Framework for Research, and 3) The Path Forward [12] [13]. The Review of Current Issues describes the state of science, including terminology issues; current issue trends. The Framework for Research presents goals and objectives. Finally, the path forward describes the next steps in implementing the roadmap, including explicitly identifying what will be done, prioritizing the proposed goals, and building partnerships to see the research bear fruit.

According to Camarinha [3], there are ten steps in developing a roadmap, namely: 1) Characterize and consolidate the baseline, 2) Perceive trends and design scenarios, 3) Elaborate, 4) Identify the gap between the current baseline and the desired vision, 5, Compile Action design, 6) Verification of planned actions, 7) Time planning and other particular actions, 8) Finalization of road map diagram definitions, 9. Conduct Consultations and Improvements, 10) Conduct consolidation.

Another reason that strengthens the need to prepare a roadmap for education science research is that education science has experienced more severe challenges with the development of time so far. Educational Science is experiencing an evolution of ambiguity, both in Indonesia and internationally; the lack of research on the science of education itself and the growing field of Educational Science focused more on studying other aspects such as the teaching-learning process [14]. To answer these challenges, the Faculty of Educational Sciences, Surabaya State University (FIP UNESA), as a center for the development of Educational Sciences, need 
to reconstruct an adaptive and responsive educational research study policy with consistent and firm direction.

A research roadmap or research roadmap has three essential components that must be interrelated with each other. The three components are 1) research activities that have been done, 2) research activities that in this period will be done, and 3) research activities in the next period that will guide a researcher to achieve his ultimate goal. Thus, the road map will clearly show the connection between research activities that have been, are, and will be done by a researcher.

FIP Unesa's research road map is also determined from the search for human resource capabilities of lecturers, especially for the field of research, the foundation of software and hardware owned by the lecturers concerned, the existing collection of researchers (domains).

The determination of a focus or niche (niche) or research theme is also planned based on the expertise possessed by FIP Unesa researchers. The focus of research or excellence is not a dream; excellence is where we excel (the bottom-up process through identifying fundamental competencies from a researcher's track record) and can compete on an international scale (by intelligently choosing unique topics). Excellent research should provide a solution to the problem of a smart way to bring FIP Unesa to the forefront of knowledge development to advance the privilege of FIP Unesa as a Faculty that produces a dignified and competitive educational force. Therefore, the involvement of various researchers and research team groups in monodisciplinary, multi-disciplinary, and even interdisciplinary research clusters or interest groups based on relevant research focus and excellent research groups is a unique feature of FIP Unesa.

The roadmap is expected to be a guide for the entire academic community of the Faculty of Education in particular to meet the standards of feasibility and research performance of both lecturers and students. In addition, it can improve the preparation and education of human resources within the University.

\section{METHODS}

This research includes development research, which is to develop a roadmap for education science research. This study adopts the ADDIE approach commonly used in educational programs (with five stages: Analyze, Design, Develop, Implement, Evaluation; [15]. The instrument used was an evaluation scale questionnaire on usability, eligibility, and accuracy of the product. This scale is to gather expert opinions on product acceptability. Data analysis was performed quantitatively and qualitatively. Quantitative data were analyzed by statistical analysis. While qualitative data in the form of comments, suggestions, criticisms, analyzed qualitatively.

\section{RESULTS}

\subsection{Need Assessment}

Needs assessment is intended to produce knowledge about the roadmap of educational science research in Indonesia and abroad. The need assessment results are analyzed, and a theoretical study is conducted to find a better research roadmap compared to the roadmap prepared in the period 2016-2020. Need assessment is done by compiling and analyzing the existing research roadmap documents, disseminating instruments to Kajur and various parties to obtain input on the roadmap that will be prepared. Furthermore, the results of data collection were analyzed qualitatively and descriptively quantitatively. The analysis results are conclusions that are descriptive information, which is then used as the basis of theoretical and conceptual study through literature review.

Need assessment was conducted by distributing a questionnaire on the needs of education science research roadmap to 52 respondents. The data results showed that $56.8 \%$ of respondents stated that the roadmap of educational science research is needed to guide, direct, and improve research on educational science, which can clarify and improve the existence of educational science. Respondents also stated that the roadmap of educational science research that has been prepared needs to be revised following the needs and developments of the times as well as the university's excellent research.

Based on the need assessment above, it can be concluded that it is necessary to develop a roadmap for educational science research that can guide, direct and improve research on educational science, which in turn can clarify and enhance the existence of educational science.

\subsection{Product Development}

The end product of this developmental research is the academic manuscript of the educational science research roadmap. Development of academic manuscript roadmap of educational science research based on relevant literature. Based on these references, further developed an educational science research roadmap that contains a description of: a) Introduction, b) Foundation for Development of FIP Unesa Research Roadmap c) Outline of FIP Unesa Research Roadmap, d) Goals, Strategic Programs, and Performance Indicators, e) Implementation FIP Unesa Research Roadmap, f) Conclusion.

This educational science research roadmap was developed with a development pattern adapting the 
ADDIE approach commonly used in the development of educational programs with 5 stages: Analyze, Design, Develop, Implement, Evaluation [15]. The stages of the implementation of the research with the ADDIE approach are described as follows:

The first stage of the ADDIE approach is the analysis of the needs and potential of educational science research. The research began by identifying potential and needs, studying the strategy at the university and faculty levels, and studying research trends in education in the present and future with stakeholders and experts in education. The search was conducted by searching the documents available in the Faculty of Educational Sciences; the search was also by using interviews and using a questionnaire of the needs of the educational science research roadmap.

The next stage is the prototype design stage. At this stage, what is done is to examine national and global strategic issues and research voids in the field of education as an external consideration in making a prototype by a) setting the purpose of education research based on needs analysis; b) setting the baseline for educational science research; c) setting the stage of achieving the goals of educational science research, and d) set the strategy for achieving the goals of educational science research, which is the basis of the prototype research roadmap FIP Unesa. Then proceeded to validate with experts and resource persons related to the strategic issues mentioned above, followed by reflection and revision to improve the academic manuscript roadmap of Education Science research.

The next stage is the development of an educational science research roadmap. At this stage, there is a discussion and validation on the scope and feasibility of the overall components in the prototype research roadmap with all the faculty representatives. So that various inputs were obtained from various parties before the prepared academic text was approved and implemented in the faculty of education.

Furthermore, the socialization is done within the faculty, university, and the general public, through various meetings such as seminars, conferences, websites, and others. Furthermore, the last is the monitoring stage, which is the stage to determine the feasibility of using the FIP Unesa research roadmap. Therefore, the current study's last two stages are the socialization and monitoring stages, after the education science research roadmap is approved and implemented.

Acting as an expert who provides an assessment of the product developed, four experts meet the criteria. This expert test is intended to test the level of acceptability of the FIP Unesa research roadmap according to experts and obtain a return of the shortcomings of the FIP Unesa research roadmap scientifically.

Quantitative data is data obtained from experts' assessments based on the contents of the product development questionnaire instrument using the assessment scale $0-5$. This assessment scale is a measure of acceptability with three assessment indicators that include aspects of usefulness (utility), feasibility (feasibility), and accuracy (accuracy). The scale of acceptability assessment as a result of the expert assessment is described as follows.

Usability indicators are detailed on the usefulness of the Educational Science Research Roadmap for research reference in faculty aims to increase research productivity, increase innovations, accommodate excellent research, and support and strengthen the implementation of the research process. The results of the assessment of usability indicators, the four experts assessed that the Educational Science Research Roadmap developed, useful applied in FIP Unesa. The results of this assessment shows that the average score of the experts' assessment is 4, 32. When consulted with the criteria, the results are beneficial so that the Education Science Research Roadmap can be further developed for approval in the Faculty boards as the official document of the Educational Science Research Roadmap.

The assessment of the feasibility indicators of the Educational Science Research Roadmap covers aspects of practicality and effectiveness. The four experts assess that the Educational Science Research Roadmap developed is practical in its implementation in terms of practicality.

Meanwhile, in assessing the efficiency aspects of implementation, the four experts assess that the amount of human resources needed to carry out this activity is relatively small, time is used enough, and does not cost a lot. Therefore, based on the assessment results, it is concluded that the Education Science Roadmap is efficient in its implementation. This can be concluded from the results of the expert evaluation score on the eligibility indicators (see table 5.1.). The average value of the four experts is 4.44 . Therefore, the average scores of the four experts compared with the eligibility aspect criteria indicated that the Educational Science Research Roadmap model developed was included in the eligible category.

Assessment of accuracy indicators (accuracy) is based on two sub-indicators, namely, the accuracy of the object and the accuracy of the formulation of objectives and procedures. Based on table 5.3. it can be seen that the average accuracy aspect is 4.33 . Therefore, by looking at the average accuracy assessment scores of experts and the classification of scores on these aspects of accuracy, 
it can be known that the Educational Science Research Roadmap developed is included in the appropriate category.

\section{DISCUSSION}

The results of the analysis of data from experts and users of the research roadmap developed can be described as follows.

The need assessment results showed that $58.68 \%$ of the respondents stated that the roadmap of educational science research is very necessary to guide, direct, and improve research on educational science, which in turn can clarify and improve the existence of educational science. Respondents also stated that the education science research roadmap that has been prepared, namely the research roadmap for 2016-2020, needs to be revised according to the needs and developments of the times and the university's excellent research.

The preparation of the academic manuscript of this educational science research roadmap was prepared by a small team followed by expert and user validation. Theus, the process of developing this research roadmap is in line with the opinion of Merriam-Webster [13]; NIOSH, [14], who stated that the preparation of the research roadmap does not need to be done by all members, but done by a team of experts who have a farsighted, imaginative and intelligent. Similarly, the process of preparing a roadmap for educational science is in line with the opinion of Vähäniitty, et al. ; [16] who stated that the process of preparing a research roadmap includes identifying, evaluating, and selecting strategic alternatives that can be used to achieve the desired goals, and the resulting roadmap is communicated.

This developmental research has produced an academic manuscript of the educational science research roadmap. The roadmap of educational science research was also based on relevant literature [6] [1] [17].

Based on these references, further developed an educational science research roadmap that contains a description of a) Introduction, b) Foundation Development Faculty's Research Roadmap c) Outline of the Research Roadmap, d) Targets, Strategic Programs, and Performance Indicators, e) Implementation of the Research Roadmap, f) Conclusion.

The level of acceptability of the educational science research roadmap developed is based on three indicators, namely, aspects of utility (utility), feasibility (feasibility), and accuracy (accuracy). We performed the expert test, and the user tests to obtain this level of acceptability, the expert tests and user tests are performed. The results of member and user assessments are based on quantitative and qualitative data, which are described as follows.
The assessment results on the usability aspect show that the educational science research roadmap developed is beneficial, especially for research reference in FIP Unesa, for increasing research productivity, for increasing innovations, in accommodating excellent research, in supporting and strengthening the research process. The results of the assessment showed that the average assessment score of the experts was 4.32. When consulted with the criteria developed in this study, the results show that the educational science research roadmap developed is beneficial so that the Educational Science Research Roadmap can be further developed for approval in the Unesa FIP Senate as the official document of the Educational Science Research Roadmap.

The assessment results on the aspect of feasibility (feasibility) show that the roadmap of educational science research developed meets the aspect of feasibility. Based on the assessment results from experts, it can be concluded that the educational science research roadmap developed is included in the eligible category, with an average score of 4.44. The score when compared with the criteria developed is included in the eligible category. The results of this study are in line with the opinion of Camarinha [6], the feasibility roadmap consists of three main components: (1) formulating a baseline of the current situation, (2) the desired vision or "future", and (3) a series of structured actions to achieve the vision the.

The assessment of accuracy indicators is based on two sub-indicators, namely the accuracy of objects and the accuracy of the formulation of objectives and procedures. The results of the expert assessment know that the average aspect of accuracy is 4.33 . By looking at the average accuracy assessment scores of experts and the classification of scores on these aspects of accuracy, it can be seen that the educational science research roadmap developed is included in the appropriate category. The results of the study showed that the roadmap was prepared appropriately, in accordance with the opinion of Merriam-Webster, [12]; NIOSH, [13] states that the purpose of the research roadmap is to outline a research agenda that will guide the development of specific research programs to be conducted, both within and across disciplines, to provide answers to current scientific questions, reduce scientific uncertainty, and provide a scientific foundation. strong for future policy development.

Meanwhile, based on data in the form of suggestions and input on the educational science research roadmap developed from experts and users, revisions and improvements have been made to the educational science research roadmap prepared. Suggestions and feedback, as well as revisions can be summarized as follows. 1) arrangement in the use of sentences, 2) correction of spelling, 3) consistency of roadmap writing, 4) consistency of writing in 2021-2025, 5) cover design needs to 
be made interesting, 6) needs to include educational science roadmap, 7) statistical data the number of lecturers and research costs need to be observed, 8) improvements in SWOT analysis, 9) need to be observed the suitability of the theme with majors, 10) need to outline the process of improving understanding of research methodology, 11) need to chart Educational Research Roadmap, 12) also need to prepare PKM roadmap.

The results of this research show that the educational science research roadmap prepared meets the criteria of acceptability and effectiveness to guide, direct, and improve research on educational science, which in turn can clarify and enhance the existence of educational science.

\section{CONCLUSION}

Based on the results and discussion, the following conclusions can be formulated. 1) Based on the above need assessment, it can be concluded that it is necessary to develop an educational science research roadmap to guide, direct and improve research on educational science, which in turn can clarify and improve the existence of educational science, 2) The developed educational science research roadmap which is very useful, very worthwhile and very appropriate. 3) The educational science research roadmap developed can direct and be a handle for the entire academic community of FIP in particular to meet the standards of feasibility and research performance of both lecturers and students.

\section{REFERENCES}

[1] W. Brezinka, Philosophy of Educational Knowledge: An introduction to the foundations of science of education philosophy of education, and practical pedagogics. Boston: Kluwer Academic Publisher, 1992.

[2] I. Barnadib., Dasar-dasar kependidikan. Jakarta: Ghalia Indonesi, 1996.

[3] H.A.R. Tilaar, Membenahi Pendidikan Nasional. Jakarta: Rineka Cipta, 2002.

[4] L. Hendrowibowo., "Kajian Ilmiah Tentang Ilmu Pendidikan," Cakrawala Pendidikan, 1994 doi:10.21831/cp.v2i2.9125.

[5] O. Komar., Menemukan dan Mengembangkan Peta Ilmu Pendidikan. Laporan Penelitian. Bandung: UPI, 2003.

[6] M. L. Camarinha., \& A. Afsarmanesh.,. "A Roadmapping Methodology for Strategic Research on VO", In Collaborative networked organizations A research agenda for emerging business models, (L.M. Camarinha-Matos, H. Afsarmanesh, Editors),
Kluwer Academic Publishers, ISBN 1- 4020-78234, Mar 2004.

[7] D. Vlachopoulos., "Assuring Quality in E-Learning Course Design: The Roadmap. International Review of Research," in Open and Distributed Learning, vol.17, no.6, pp.183-205, 2016. https://doi.org/ 10.19173/ irrodl.v17i6.2784

[8] I.H. Thora., \& P. Beverly., "Drafting A Research Roadmap," Procedia - Social and Behavioral Sciences, vol. 119. Pp.719 - 724, 2014.

[9] M.A.H. Masud., J. Yong., X. Huang., "Cloud Computing for Higher Education: A Roadmap," Proceedings of the 2012 IEEE 16th International Conference on Computer Supported Cooperative Work in Design, 2012.

[10] A. Elqorni., Mengenal Roadmap (Peta Jalan) Penelitian. Diakses dari https://elqorni.wordpress.com/2019/08/16/mengena 1-roadmap-peta-jalan-penelitian/, 29 Mei 2020.

[11] E. Kim., S. Yao., Agogino., A. Merner., "Design Roadmapping: Challenges And Opportunities," Proceedings of the 20th International Conference on Engineering Design (ICED15), Milan, Italy, 27.30.07.2015

[12] Merriam-Webster., Merriam-Webster, 2020. online dictionary. http://www. merriamwebster.com/dictionary/road+map.

[13] NIOSH (National Institute for Occupational Safety and Health). 2019. a. Revised draft. NIOSH current intelligence bulletin. Asbestos fibers and other elongated mineral particles: State of the science and roadmap for research. January 2009. Department of Health and Human Services, Centers for Disease Control and Prevention, National Institute for Occupational Safety and Health. http://www.cdc.gov/niosh/ docket/pdfs/NIOSH-099b/099B-040109 Asbestos NAReviewDoc.pdf (accessed September 18, 2019).

[14] A.S. Makmun., Psikologi Remaja. Jakarta: Rineka Cipta, 2004.

[15] R.M., Branch., Instructional Design: The ADDIE Approach. Springer, 2015 DOI: 10.1007/978-0 387-09506-6

[16] Vähäniitty, et al. "An approach to product roadmapping in small software product businesses. In ECSQ2002), Conference Notes (pp. 12-13), 2002.

[17] M. Howlett \& M. Ramesh., Studying public policy: Policy cycles and policy subsystems. Toronto, ON: Oxford University Press Canada, 2003. 